Federal Reserve Bank of Minneapolis

Research Department Staff Report 193

Revised January 1999

\title{
The Jointly Optimal Inflation Tax, Income Tax Structure, and Transfers
}

\author{
Preston J. Miller* \\ Federal Reserve Bank of Minneapolis
}

\begin{abstract}
The welfare-maximizing income tax structure, rate of money creation, and amounts of intergenerational transfers are jointly determined for given rates of government consumption. When government consumption is zero, it is found for the parameter values examined that the income tax structure is progressive, the rate of money change is negative, and positive transfers are made to the old. As government consumption increases, the tax structure's progressivity declines and turns increasingly regressive, the rate of money change rises, and transfers decrease. It is found that the bulk of the increase in government consumption is optimally financed by a cut in transfers.
\end{abstract}

*The author thanks Dan Chin for his capable research assistance. The views expressed herein are those of the author and not necessarily those of the Federal Reserve Bank of Minneapolis or the Federal Reserve System. 
Suppose government consumption permanently increases. Should greater or diminished use be made of the inflation tax? Should the income tax be made more or less progressive? Should intergenerational transfers be increased or decreased? In this paper the answers to all three of these questions are jointly determined.

The model used for analysis is the third in a progression. The first in the progression, Miller (1984), assumed a real economy with serially independent shocks to technology. The second, Miller (1993a), extended the original model by incorporating endogenously valued fiat money in fixed supply. The model in the current paper extends the model in Miller (1993a) in three ways by allowing

1. positive rates of government consumption,

2. nonzero rates of money growth, and

3. serial correlation in the technology shocks.

With the exception of these noted differences, the economic environment of all three models is the same.

The general modeling approach taken here shares many attributes of other modern approaches to public finance. The model is general equilibrium with explicit description of endowments, production processes, information availability, market structure, government policies, and individual optimization problems. The general equilibrium approach offers at least three advantages over a macroeconomic approach. First, it assures internal consistency of behavioral functions, since they are all derived within a common economic environment. Second, behavioral relations are invariant to changes in policy rules, that is, the model is not subject to the Lucas critique, because individual decision rules explicitly depend on the policy rules. Third, the policy objectives can be stated in terms of individual welfare. This follows because the utilities of all individuals can be determined as functions of their consumption and leisure. 
Like other modern approaches, the model is dynamic. Thus, public finance policies affect the allocation of consumption and leisure over time and distort by altering the marginal rates of intertemporal substitution.

In addition, the model incorporates fundamental uncertainty in the form of random shocks to technology. Since the model's structure implies that private insurance against these shocks is not feasible, it allows a role for government insurance which takes the form of automatic economic stabilization.

Despite these similarities to other modern approaches, the modeling approach taken here differs from the others in some significant ways. ${ }^{1}$ Other models tend to share these characteristics:

- They include representative agents who are infinitely lived.

- They include physical capital.

- They employ fairly general functional forms and stochastic processes.

- They can be calibrated.

While my model has none of these features, it has others that the more standard models tend not to have:

- It has a nonlinear income tax.

- It allows an endogenously valued fiat money.

- It determines a socially optimal scale of intergenerational tax/transfers; e.g., social security.

If one is to stray from the flock, there is a burden to demonstrate what is gained. I believe the primary gain is that my model provides answers and insights to public finance questions which are not even addressed in the standard models. The present model also provides useful examples and counterexamples from a fully specified general equilibrium model which take the form:

- "It is possible that . . ", or 
- "It is not always true that ...".

However, the judgment about whether this line of research is useful must be made by the readers. So to aid in this judgment, I briefly describe the common structure of the three models in the progression, note how each model extends the one before it, and then list the main findings and insights from each model. After this lengthy introduction, I formally describe the present model, the solution, and the policy implications.

\section{The Models and Their Messages}

The basic structure of all the models in the progression is the same. There is a constant population of two-period lived agents. The agents divide their time between work and leisure in their first period of life and retire in their second period. There are constant returns to labor input, but the return is random and can take on a "good" or "bad" value. The return shock occurs and then the

young agents come on the scene, so that no private risk-sharing is possible. Agents care about consumption and leisure in each period of life. The government taxes agents when they are young and working and transfers the proceeds to agents who, in the second period of their lives, are retired. The government's objective is to maximize welfare of the young and the future generations, which is shown to be equivalent to minimizing the sum of "distortion" and "instability."

In the first model in the progression, shocks to technology are serially uncorrelated, there is no government consumption, and there is no money, so that all taxes are real. Income taxes are nonlinear: When marginal tax rates rise with income levels the tax is "progressive;" when they fall with income levels, the tax is "regressive." In the second version of the model, the initial old are endowed with a fixed stock of fiat money. Although the total stock of money is fixed over time, there is a difference in this version of the model between real and nominal income taxes. Real taxes relate real tax revenues to real income, while nominal taxes relate nominal tax revenues to nominal 
income. The difference between the two occurs because tax schedules are nonlinear. In the third, and present, version of the model, shocks to technology can be serially correlated, the government can consume at a constant rate, and the money stock can grow or shrink at a constant rate.

In the first model, in which there is no serial correlation to technology shocks, no government consumption, and no money, the main findings are:

1. Reducing economic distortion should not be the sole goal of tax policy. Reducing economic instability is also a proper goal. ${ }^{2}$

2. It is possible that government tax policies can reduce the instability in income while increasing economic instability in terms of consumption and leisure.

3. Although there is a role for reducing economic instability, a regressive income tax, which increases instability relative to a linear or progressive tax, appears optimal.

In the second model, which differs from the first only by the inclusion of a fixed stock of fiat money, the main findings are:

1. Different tax policy implications can follow in real and monetary models. This basically results from the two having different market structures.

2. The optimal income tax structure can be progressive. In a monetary model, as compared to a real model, the insurance, or stabilization, role of the tax/transfer system becomes relatively more important than its redistributive role, and a progressive tax provides insurance, or stability.

3. A nominal income tax (nonindexed) may be preferred to a real income tax (indexed). In this model, the nominal tax has the price level as a shifter, which allows a regressive structure in each state but higher tax rates in the good state than in the bad. 
4. One tax can imply a higher mean and lower variance of real income than another and still be less desirable. Thus, evaluating policies according to the behavior of a proxy like real GDP can be misleading.

In the present model, there can be serial correlation to technology shocks, positive government consumption, and steady growth or shrinkage in the money stock. While the findings from the previous two versions of the model have been described more fully in the previous publications, the findings from the present version of the model have not been described at all. So, instead of just giving a general overview, I first describe the main findings and then provide an intuitive explanation for them.

The findings are based on a numerical analysis of the model. The numerical parameter values are chosen to produce labor supply functions with reasonable properties:

- Labor supply is between 0 and 1 , where 1 is all the time available.

- Labor supply is increasing in its rate of return. That is, more labor is supplied when productivity is relatively high and when income taxes are relatively low.

A sensitivity analysis is conducted with respect to parameter value choices, but it appears that the labor supply specifications are the only crucial ones.

The major findings from the numerical analysis include:

1. For all parameter values examined, the government optimally runs a surplus and shrinks the stock of money.

2. As government consumption increases,

a. Income tax revenues increase,

b. The income tax structure becomes more regressive,

c. The deflation subsidy decreases, and

d. Transfers decline. 
3. The bulk of the increase in government consumption is accommodated by a decline in transfers.

4. Higher government consumption results in higher output and lower prices. However, since it reduces consumption and leisure, it also results in lower welfare.

5. Greater serial correlation increases welfare by making outcomes more predictable. Thus, it diminishes the need for transfers to insure against instability and allows lower taxation.

The first finding is a bit surprising, since the model has overlapping generations and distorting taxes. The finding holds when government consumption is zero. That suggests that when an optimal tax/transfer scheme exists, a rate of deflation is required to provide the proper incentive to private saving.

The second set of findings suggests that when all forms of financing distort, the pain should be spread over all of them. As more taxes are raised, distortion becomes increasingly more important than instability, so that the income tax structure moves from progressive to regressive.

Reducing transfers to the old is the least distorting way to accommodate higher government consumption, and that explains the third finding. In a dynamic model, this does not translate into stealing from the old to give to the young. At some time all agents (except the current old) are both young and then later old. Thus, reducing transfers amounts to a tax on second-period consumption. Increasing this tax to cover higher government consumption allows agents to best adjust their demands for consumption, leisure, and insurance.

The fourth finding is intuitive with respect to output but not with respect to prices. When government consumption is financed primarily by lower transfers, agents' utility loss is spread over the utilities associated with consumption and leisure. By accepting less leisure, agents work more and produce more. But since leisure does not wholly absorb the loss, output increases by less than 
government consumption. The finding with respect to prices is explained by the government's response to its greater consumption and by agents' desire to increase private savings. In this model the government reduces transfers by close to the amount of its increase in consumption, so government expenditures and the budget deficit barely budge. However, since the brunt of additional financing for government consumption is borne by a tax on second-period consumption, agents desire to increase their private saving, so that their loss in income is distributed in a more balanced way between first- and second-period consumption. The demand for greater savings implies a lower price level (a higher value of savings).

The fifth finding seems intuitive. It follows that with lower taxes, agents decide to "make more hay when the sun shines." Although their utility declines from having less leisure, the additional consumption they enjoy is more than offsetting.

In the text that follows, the model and its solution are formally described, and results of numerical exercises are reported and discussed. The paper concludes with an extended discussion concerning the applicability of the model's main findings.

\section{The Model}

\section{Population}

In each period $\mathrm{N}$ identical individuals are born. Each individual lives two periods. Thus, in each period there are $\mathrm{N}$ "old" in the last period of their lives and $\mathrm{N}$ "young" in the first period of their lives. Without loss of generality it is assumed that $\mathrm{N}=1$.

\section{Individual Welfare}

Individual preferences are represented by a time-separable utility function in consumption and leisure:

$$
\mathrm{W}=\mathrm{U}\left(\mathrm{c}_{1}, \tilde{\mathrm{L}}_{1}\right)+\beta \mathrm{U}\left(\mathrm{c}_{2}, \tilde{\mathrm{L}}_{2}\right)
$$


where for an individual of a given generation $c_{i}$ is consumption in the $i^{\text {th }}$ period of life; $\tilde{L}_{i}$ is leisure in the $\mathrm{i}^{\text {th }}$ period of life, $0 \leq \tilde{\mathrm{L}}_{\mathrm{i}} \leq 1$; and the contemporaneous utility function $\mathrm{U}$ is assumed to be differentiable and concave.

Special assumptions are made about $\mathrm{U}$ and its arguments in order to make the numerical analysis tractable. In particular, it is assumed that

$$
\mathrm{U}(\mathrm{c}, \tilde{\mathrm{L}})=-\mathrm{A}(\mathrm{c}-\mathrm{c} *)^{2}-\mathrm{B}\left(\tilde{\mathrm{L}}-\tilde{\mathrm{L}}^{*}\right)^{2}
$$

where $\mathrm{A}>0, \mathrm{~B}>0$, the satiation level of consumption $\mathrm{c}^{*}$ is at least as large as any feasible level, and the satiation level of leisure $\tilde{\mathrm{L}}^{*}$ is all the time available: $\tilde{\mathrm{L}}^{*} \equiv 1$.

\section{Endowments}

Each individual is endowed with one unit of time each period. In the first period that time is divided between leisure $\tilde{\mathrm{L}}_{1}$ and labor $\mathrm{L}: \tilde{\mathrm{L}}_{1} \geq 0, \mathrm{~L} \geq 0$, and $\tilde{\mathrm{L}}_{1}+\mathrm{L}=1$. In the second period all time goes to leisure: $\tilde{\mathrm{L}}_{2} \equiv 1$.

An individual in the current old generation is endowed with $\mathrm{M} / \mathrm{N}=\mathrm{M}$ units of fiat money.

\section{Production}

Production in each period of a perishable consumption good y is governed by the linear process

$$
\mathrm{y}^{\mathrm{k}}=\mu^{\mathrm{k}} \cdot \mathrm{L}
$$

where $\mathrm{k}=\mathrm{B}$ the bad state or $\mathrm{k}=\mathrm{G}$ the $\operatorname{good} \operatorname{state}^{3}$ and $\mu$ is a first-order Markov process such that

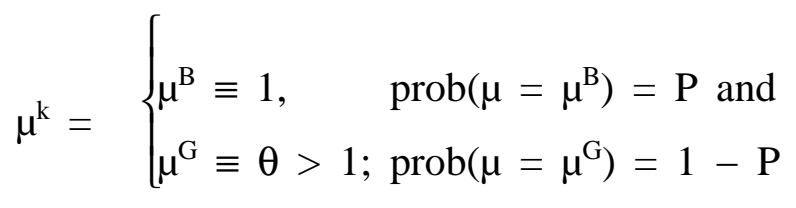




$$
\operatorname{prob}\left(\mu(\mathrm{t}+1)=\mathrm{u}^{\mathrm{k}^{\prime}} \mid \mu(\mathrm{t})=\mu^{\mathrm{k}}\right)= \begin{cases}\mathrm{q} \geq 1 / 2, & \text { if } \mathrm{k}^{\prime}=\mathrm{k} \\ 1-\mathrm{q}, & \text { if } \mathrm{k}^{\prime} \neq \mathrm{k}\end{cases}
$$

The young in any period observe $\mu$ before they decide on how much labor to supply.

\section{Exchange}

In any period the young and old exchange goods and money. The old sell money, their savings, to purchase goods. The young sell the goods they produced to acquire money, their savings. Private insurance markets cannot operate due to the assumed timing of productivity shocks. Since the current young appear after the shock to productivity has occurred, they cannot insure against fluctuations in first-period income. They would like to insure against fluctuations in second-period income; but only the current old could sell the insurance, and they will not be around in the next period to pay off. The absence of private insurance is meant to reflect that in the real world agents cannot fully insure their labor income against business cycle risks.

\section{Government}

On a continuing basis the government consumes at a constant, state-independent real rate G. It also spends in real terms for state-contingent transfers $\operatorname{Tr}^{\mathrm{kk}^{\prime}}(\mathrm{t}+1)$, where the date of the transfers is taken to be $\mathrm{t}+1, \mathrm{k}^{\prime}$ is the state at $\mathrm{t}+1$, and $\mathrm{k}$ is the state at date $\mathrm{t}$; that is, $\mu(\mathrm{t})=\mu^{\mathrm{k}}$ and $\mu(\mathrm{t}+1)=\mu^{\mathrm{k}^{\prime}}$, where $\mathrm{k}, \mathrm{k}^{\prime}=\mathrm{B}$ or $\mathrm{G}$.

The government has two sources of revenue. One is a real, quadratic income tax which provides real revenue at time $\mathrm{t}+1$ of $\mathrm{T}^{\mathrm{k}^{\prime}}(\mathrm{t}+1)=\tau_{1} \mathrm{y}^{\mathrm{k}^{\prime}}(\mathrm{t}+1)+\tau_{2}\left[\mathrm{y}^{\mathrm{k}^{\prime}}(\mathrm{t}+1)\right]^{2}$. The government can also raise seignorage by expanding the stock of money at a constant rate $\lambda$; that is, $M(t+1)=(1+\lambda) M(t)$ for all $\mathrm{t}$, where $\lambda \geq-1$. The government's current-dollar, point-in-time budget constraint at date $\mathrm{t}+$ 1 is, then, 


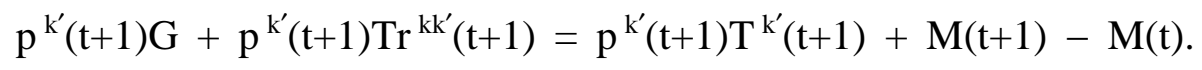

From the definitions above, the budget constraint can be expressed in real terms as

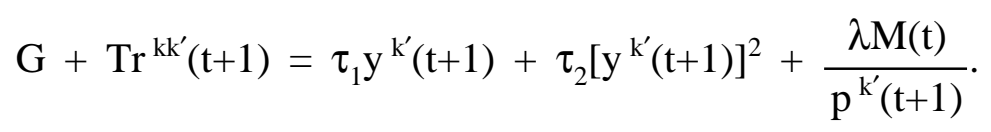

\section{Methodology}

The aim of the analysis is to trace out the locus of optimal policy choice variables $\left(\hat{\tau}_{1}, \hat{\tau}_{2}, \hat{\lambda}\right)$ as functions of the policy parameter G. For a given G, the search for the optimal policy choice variables is done in two steps. In the first step, individual demand functions and market-clearing conditions are found (numerically) for arbitrary values of $\tau_{1}, \tau_{2}$, and $\lambda$. From these expressions it is also possible to determine allocations of consumption and leisure, and hence utility, for agents of all generations. Analysis pertaining to this first step is described under the heading "equilibrium."

In the second step values for $\tau_{1}, \tau_{2}$, and $\lambda$ that maximize social welfare are found. Social welfare is taken to be the discounted sum of the unconditional utilities of all agents in current and future generations. An interpretation is that a social planner at date $t$, who does not observe the current period's productivity shock, seeks to maximize the weighted sum of utilities of current and future agents, where the sum of the weights converges to a finite value. Analysis pertaining to this second step is described under the heading "optimization."

The analyses of equilibrium and optimization are simplified by recognizing that equilibria must be stationary. Because there is no capital in the model, because the government choice variables are assumed to be time independent, and because the productivity shock process is assumed to be first-order Markov, current-period individual demand functions and market-clearing conditions depend only on the productivity shocks in the immediate past and current periods. Stationarity also implies that the unconditional expected utilities of agents from the current and all future generations must be 
the same. Thus, maximizing the social welfare function is equivalent to maximizing the unconditional expected utility of the current young.

\section{Equilibrium}

An equilibrium consists of sequences of prices and quantities such that at each date markets clear and agents maximize utility subject to their budget constraints. There are three markets in the model: labor, consumption goods, and money. By Walras' Law, equilibrium in any two implies equilibrium in the third. In this analysis the two markets are taken to be labor and money.

In a stationary equilibrium excess demand functions for consumption, labor, and real money holdings depend on the previous state $\mu(t-1)$ and the current state $\mu(t)$, but the dependence is time invariant. Consumption in the second period of an agent's life, then, depends on the state of technology in both the first and second periods of that agent's life. However, decisions made in the first period of an agent's life do not depend on the state of technology before that agent was born. Therefore, consumption demand in the first period of life, labor supply, and real money demand depend only on the current state. It follows that a stationary equilibrium for given parameter values can be found by solving for $\hat{\mathrm{L}}^{\mathrm{B}}, \hat{\mathrm{L}}^{\mathrm{G}}, \hat{\mathrm{m}}^{\mathrm{B}}$, and $\hat{\mathrm{m}}^{\mathrm{G}}$, where $\hat{\mathrm{L}}^{\mathrm{i}}$ is the desired amount of labor supplied in state $i$ and $\hat{\mathrm{m}}^{\mathrm{i}}$ is the desired holdings of real balances in state $\mathrm{i} ; \hat{\mathrm{m}} \equiv \mathrm{S} \cdot \mathrm{M}$, and $\mathrm{S} \equiv 1 / \mathrm{p}$. Then the equilibrium, which requires market-clearing in the labor and money markets, recognizes that labor demand is identically equal to labor supply and that the supply of money is given exogenously by $M(t)=(1+\lambda)^{t} M(0)$, and without loss of generality $M(0)$ is taken to be 1.

The individual's choice problem when young is to maximize expected utility over the two periods conditional on observation of the current state and subject to the period-by-period budget constraints:

$$
\max _{\mathrm{L}, \mathrm{m}} \mathrm{E}[\mathrm{W} \mid \mu(\mathrm{t})]=-\mathrm{A}\left[\left(\mathrm{c}_{1}-\mathrm{c}^{*}\right)^{2} \mid \mu(\mathrm{t})\right]-\mathrm{B}\left[\mathrm{L}^{2} \mid \mu(\mathrm{t})\right]-\beta \mathrm{AE}_{\mu(\mathrm{t}+1)}\left[\left(\mathrm{c}_{2}-\mathrm{c}^{*}\right)^{2} \mid \mu(\mathrm{t})\right]
$$


We first solve for $\mathrm{W}_{2}^{\mu(\mathrm{t})} \equiv \mathrm{E}_{\mu(\mathrm{t}+1)}\left[\left(\mathrm{c}_{2}-\mathrm{c}^{*}\right)^{2} \mid \mu(\mathrm{t})\right]$, the expectation of the second-period component to utility after observing $\mu(\mathrm{t})$ but before observing $\mu(\mathrm{t}+1)$. The maximization problem for the second period is identical to that of the initial old: the solution is to spend all the resources available on consumption:

$$
c_{2}^{\mathrm{ij}} \equiv\left(c_{2} \mid \mu(t)=i, \mu(t+1)=j\right)=\operatorname{Tr}^{\mathrm{ij}}(\mathrm{t}+1)+\mathrm{S}^{\mathrm{j}}(\mathrm{t}+1) \mathrm{M}^{\mathrm{i}}(\mathrm{t}) ; \quad \mathrm{i}, \mathrm{j}=\mathrm{B} \text { or } \mathrm{G}
$$

Since $\mathrm{m}^{\mathrm{i}}=\mathrm{S}^{\mathrm{i}}(\mathrm{t}) \mathrm{M}^{\mathrm{i}}(\mathrm{t})$, we can write

$$
c_{2}^{i j}=\operatorname{Tr}^{i j}+X^{i j} \cdot m^{i} ; \quad i, j=B \text { or } G \text { and } X^{i j} \equiv S^{j}(t+1) / S^{i}(t)
$$

Now let $R \equiv(1+\lambda)^{-1}$. It follows by stationarity with $m^{i}(t)=m^{i}$ that

$$
\begin{aligned}
& X^{B B}=X^{G G}=R \\
& X^{B G}=R m^{G} / m^{B}
\end{aligned}
$$

and

$$
\mathrm{X}^{\mathrm{GB}}=\mathrm{Rm}^{\mathrm{B}} / \mathrm{m}^{\mathrm{G}} \text {. }
$$

Using the substitutions above, we can now write

$$
\mathrm{W}_{2}^{\mathrm{B}}=\mathrm{q}(1-\mathrm{q})\left[\left(\operatorname{Tr}^{\mathrm{BG}}-\operatorname{Tr}^{\mathrm{BB}}\right)+\left(\mathrm{X}^{\mathrm{BG}}-\mathrm{X}^{\mathrm{BB}}\right) \mathrm{m}^{\mathrm{B}}\right]^{2}+\left(\overline{\mathrm{Tr}}^{\mathrm{B}}+\overline{\mathrm{X}}^{\mathrm{B}} \mathrm{m}^{\mathrm{B}}-\mathrm{c}^{*}\right)^{2}
$$

where

$$
\begin{aligned}
& \overline{\operatorname{Tr}}^{\mathrm{B}} \equiv \mathrm{E}\left[\operatorname{Tr} \mid \mu(\mathrm{t})=\mu^{\mathrm{B}}\right]=\mathrm{q} \operatorname{Tr}^{\mathrm{BB}}+(1-\mathrm{q}) \operatorname{Tr}^{\mathrm{BG}} \\
& \bar{X}^{\mathrm{B}} \equiv \mathrm{E}\left[\mathrm{X} \mid \mu(\mathrm{t})=\mu^{\mathrm{B}}\right]=\mathrm{qX}^{\mathrm{BB}}+(1-\mathrm{q}) \mathrm{X}^{\mathrm{BG}}
\end{aligned}
$$

and

$$
\mathrm{W}_{2}^{\mathrm{G}}=\mathrm{q}(1-\mathrm{q})\left[\left(\mathrm{Tr}^{\mathrm{GG}}-\mathrm{Tr}^{\mathrm{GB}}\right)+\left(\mathrm{X}^{\mathrm{GG}}-\mathrm{X}^{\mathrm{GB}}\right) \mathrm{m}^{\mathrm{G}}\right]^{2}+\left(\overline{\mathrm{T}} \mathrm{r}^{\mathrm{G}}+\overline{\mathrm{X}}^{\mathrm{G}} \mathrm{m}^{\mathrm{G}}-\mathrm{c}^{*}\right)^{2}
$$

where

$$
\overline{\operatorname{Tr}}^{\mathrm{G}} \equiv \mathrm{E}\left[\operatorname{Tr} \mid \mu(\mathrm{t})=\mu^{\mathrm{G}}\right]=\mathrm{qTr}^{\mathrm{GG}}+(1-\mathrm{q}) \operatorname{Tr}^{\mathrm{GB}}
$$


$\bar{X}^{\mathrm{G}} \equiv \mathrm{E}\left[\mathrm{X} \mid \mu(\mathrm{t})=\mu^{\mathrm{G}}\right]=\mathrm{q} \mathrm{X}^{\mathrm{GG}}+(1-\mathrm{q}) \mathrm{X}^{\mathrm{GB}}$.

When they are young, the agents face one budget constraint if $\mu(t)=\mu^{B}$ and another if $\mu(t)=$ $\mu^{\mathrm{G}}$. The constraints are

$$
\text { for } \mu(t)=\mu^{B}, \quad c_{1}^{B}=\left(1-\tau_{1}\right) y^{B}-\tau_{2} y^{B^{2}}-m^{B}=\left(1-\tau_{1}\right) L^{B}-\tau_{2} L^{B^{2}}-m^{B}
$$

and

$$
\text { for } \mu(t)=\mu^{G}, \quad c_{1}^{G}=\left(1-\tau_{1}\right) y^{G}-\tau_{2} y^{G^{2}}-m^{G}=\left(1-\tau_{1}\right) \theta L^{G}-\tau_{2} \theta^{2} L^{G^{2}}-m^{G} \text {. }
$$

Using the expressions derived above, we can write the conditional maximization problems of the young in terms of the four decision variables $\mathrm{L}^{\mathrm{B}}, \mathrm{L}^{\mathrm{G}}, \mathrm{m}^{\mathrm{B}}$, and $\mathrm{m}^{\mathrm{G}}$ :

for $\mu(t)=\mu^{B}$,

$\max _{L^{\mathrm{B}}, \mathrm{m}^{\mathrm{B}}} \mathrm{E}\left[\mathrm{W} \mid \mu^{\mathrm{B}}\right]=-\mathrm{A}\left[\left(1-\tau_{1}\right) \mathrm{L}^{\mathrm{B}}-\tau_{2} \mathrm{~L}^{\mathrm{B}^{2}}-\mathrm{m}^{\mathrm{B}}-\mathrm{c}^{*}\right]^{2}-\mathrm{BL}^{\mathrm{B}^{2}}-\beta A \mathrm{~W}_{2}^{\mathrm{B}}$

and for $\mu(t)=\mu^{\mathrm{G}}$,

$\max _{\mathrm{L}^{\mathrm{G}, \mathrm{m}^{\mathrm{G}}}} \mathrm{E}\left[\mathrm{W} \mid \mu^{\mathrm{G}}\right]=-\mathrm{A}\left[\left(1-\tau_{1}\right) \theta \mathrm{L}^{\mathrm{G}}-\tau_{2} \theta^{2} \mathrm{~L}^{\mathrm{G}^{2}}-\mathrm{m}^{\mathrm{G}}-\mathrm{c}^{*}\right]^{2}-\mathrm{BL}^{\mathrm{G}^{2}}-\beta A \mathrm{~W}_{2}^{\mathrm{G}}$.

These maximization problems produce four first-order conditions for the four decision variables:

$$
\begin{aligned}
& 2 \mathrm{~A} \tau_{2}^{2} \hat{\mathrm{L}}^{\mathrm{B}^{3}}-3 \mathrm{~A}\left(1-\tau_{1}\right) \tau_{2} \hat{\mathrm{L}}^{\mathrm{B}^{2}}+\left\{\mathrm{A}\left[\left(1-\tau_{1}\right)^{2}+2 \tau_{2}\left(\hat{\mathrm{m}}^{\mathrm{B}}+\mathrm{c}^{*}\right)\right]+\mathrm{B}\right\} \hat{\mathrm{L}}^{\mathrm{B}} \\
&-\mathrm{A}\left(1-\tau_{1}\right)\left(\hat{\mathrm{m}}^{\mathrm{B}}+\mathrm{c}^{*}\right)=0
\end{aligned}
$$

$$
\begin{aligned}
& 2 \mathrm{~A} \tau_{2}^{2} \theta^{3} \hat{\mathrm{L}}^{\mathrm{G}^{3}}-3 \mathrm{~A}\left(1-\tau_{1}\right) \tau_{2} \theta^{2} \hat{\mathrm{L}}^{\mathrm{G}^{2}}+\left\{\mathrm{A}\left[\left(1-\tau_{1}\right)^{2}+2 \tau_{2}\left(\hat{\mathrm{m}}^{\mathrm{G}}+\mathrm{c}^{*}\right)\right]+\mathrm{B} / \theta\right\} \theta \hat{\mathrm{L}}^{\mathrm{G}} \\
&-\mathrm{A}\left(1-\tau_{1}\right)\left(\hat{\mathrm{m}}^{\mathrm{G}}+\mathrm{c}^{*}\right)=0
\end{aligned}
$$

$$
\begin{aligned}
\left(1+\beta \mathrm{qR} \mathrm{R}^{2}\right) \hat{\mathrm{m}}^{\mathrm{B}^{2}}-\left\{\left[\left(1-\tau_{1}\right) \hat{\mathrm{L}}^{\mathrm{B}}-\tau_{2} \hat{\mathrm{L}}^{\mathrm{B}^{2}}-\mathrm{c}^{*}\right]-\beta \mathrm{qR}\left(\operatorname{Tr}^{\mathrm{BB}}-\mathrm{c}^{*}\right)\right\} \hat{\mathrm{m}}^{\mathrm{B}} \\
+\beta(1-\mathrm{q}) \mathrm{R}^{\mathrm{G}}\left(\operatorname{Tr}^{\mathrm{BG}}+\mathrm{R} \hat{\mathrm{m}}^{\mathrm{G}}-\mathrm{c}^{*}\right)=0
\end{aligned}
$$

and 
(iv)

$$
\begin{aligned}
\left(1+\beta \mathrm{qR}^{2}\right) \hat{\mathrm{m}}^{\mathrm{G} 2}- & \left\{\left[\left(1-\tau_{1}\right) \theta \hat{\mathrm{L}}^{\mathrm{G}}-\tau_{2} \theta^{2} \hat{\mathrm{L}}^{\mathrm{G}^{2}}-\mathrm{c}^{*}\right]-\beta \mathrm{qR}\left(\operatorname{Tr}^{\mathrm{GG}}-\mathrm{c}^{*}\right)\right\} \hat{\mathrm{m}}^{\mathrm{G}} \\
+ & \beta(1-\mathrm{q}) \mathrm{R} \hat{\mathrm{m}}^{\mathrm{B}}\left(\operatorname{Tr}^{\mathrm{GB}}+\mathrm{R} \hat{\mathrm{m}}^{\mathrm{B}}-\mathrm{c}^{*}\right)=0 .
\end{aligned}
$$

From the government's budget constraint we have that transfers in period $t$ are independent of the state in $\mathrm{t}-1$, so that

$$
\operatorname{Tr}^{\mathrm{B}} \equiv \operatorname{Tr}^{\mathrm{BB}}=\operatorname{Tr}^{\mathrm{GB}}=\tau_{1} \hat{\mathrm{L}}^{\mathrm{B}}+\tau_{2} \hat{\mathrm{L}}^{\mathrm{B}^{2}}+(1-\mathrm{R}) \hat{\mathrm{m}}^{\mathrm{B}}-\mathrm{G}
$$

and

$$
\operatorname{Tr}^{\mathrm{G}} \equiv \operatorname{Tr}^{\mathrm{BG}}=\operatorname{Tr}^{\mathrm{GG}}=\tau_{1} \theta \hat{\mathrm{L}}^{\mathrm{G}}+\tau_{2}\left(\theta \hat{\mathrm{L}}^{\mathrm{G}}\right)^{2}+(1-\mathrm{R}) \hat{\mathrm{m}}^{\mathrm{G}}-\mathrm{G}
$$

After these substitutions into (iii) and (iv) are made, those two equations can be written as

(iii) ${ }^{\prime} \quad a \hat{\mathrm{m}}^{\mathrm{B}^{2}}+b \hat{\mathrm{m}}^{\mathrm{B}}+c \hat{\mathrm{m}}^{\mathrm{G}^{2}}+d \hat{\mathrm{m}}^{\mathrm{G}}=0$

and

(iv) $\quad a \hat{\mathrm{m}}^{\mathrm{G}^{2}}+e \hat{\mathrm{m}}^{\mathrm{G}}+c \hat{\mathrm{m}}^{\mathrm{B}}+f \hat{\mathrm{m}}^{\mathrm{B}}=0$

where

$$
\begin{aligned}
& a \equiv 1+\beta \mathrm{qR} \\
& b \equiv(1-\beta \mathrm{qR}) \mathrm{c}^{*}-\left[1-(1+\beta \mathrm{qR}) \tau_{1}\right] \hat{\mathrm{L}}^{\mathrm{B}}+(1+\beta \mathrm{qR}) \tau_{2} \hat{\mathrm{L}}^{\mathrm{B}^{2}}-\beta \mathrm{qRG} \\
& c \equiv \beta(1-\mathrm{q}) \mathrm{R} \\
& d \equiv c \cdot\left[\tau_{1} \theta \hat{\mathrm{L}}^{\mathrm{G}}+\tau_{2}\left(\theta \hat{\mathrm{L}}^{\mathrm{G}}\right)^{2}-\mathrm{G}-\mathrm{c}^{*}\right] \\
& e \equiv(1-\beta \mathrm{qR}) \mathrm{c}^{*}-\left[1-(1+\beta \mathrm{qR}) \tau_{1}\right] \theta \hat{\mathrm{L}}^{\mathrm{G}}+(1+\beta \mathrm{qR}) \tau_{2}\left(\theta \hat{\mathrm{L}}^{\mathrm{G}}\right)^{2}-\beta \mathrm{qRG} \\
& f \equiv c \cdot\left[\tau_{1} \hat{\mathrm{L}}^{\mathrm{B}}+\tau_{2} \hat{\mathrm{L}}^{\mathrm{B}^{2}}-\mathrm{G}-\mathrm{c}^{*}\right] .
\end{aligned}
$$

From (iii)' and (iv)' it is possible to transform the variables using $\phi \equiv \hat{\mathrm{m}}^{\mathrm{G}} / \hat{\mathrm{m}}^{\mathrm{B}}$. This generates two equations to replace (iii)' and (iv)'

$$
(c e-a d) \phi^{3}+(c f-a b) \phi^{2}+(a e-c d) \phi+(a f-b c)=0
$$

and 


$$
\hat{\mathrm{m}}^{\mathrm{B}}=-(b+d \phi) /\left(a+c \phi^{2}\right)
$$

System (i), (ii), and (v), then, is three cubic equations in three unknowns: $\hat{\mathrm{L}}^{\mathrm{B}}, \hat{\mathrm{L}}^{\mathrm{G}}$, and $\phi$. Values for $\hat{\mathrm{m}}^{\mathrm{B}}$ can easily be found from the solution by using equation (vi), and $\hat{\mathrm{m}}^{\mathrm{G}}$ can be found from the definition of $\phi: \hat{\mathrm{m}}^{\mathrm{G}} \equiv \phi \hat{\mathrm{m}}^{\mathrm{B}}$. Although the three-equation system has only known parameters in addition to the three unknowns, the unknowns appear in more than one equation, and thus a numerical solution technique is required. The solution routine postulates initial values of $\mathrm{L}^{\mathrm{B}}$ and $\mathrm{L}^{\mathrm{G}}$ such that $0<\mathrm{L}^{\mathrm{B}}<\mathrm{L}^{\mathrm{G}}<1$ and then uses a Gauss-Siedel method cycling the three equations until the values of the variables converge. The order of equations solved is first $(v)$, from which $\mathrm{m}^{\mathrm{B}}$ and $\mathrm{m}^{\mathrm{G}}$ are derived, and then (i) followed by (ii). Each time an equation is solved, the routine selects the single real root with appropriate domain: $\phi>1$ and $0<\mathrm{L}^{\mathrm{B}}<\mathrm{L}^{\mathrm{G}}<1$. From the solution values for the three unknowns all other equilibrium values can be determined from the relationships derived in the text above.

\section{Optimization}

The social planner's optimization problem can be considered as maximizing the unconditional utility of the current young EW with respect to $\tau_{1}, \tau_{2}$, and $\lambda$ for given values of parameters $\Psi \equiv$ $<\mathrm{A}, \mathrm{B}, \mathrm{c}^{*}, \beta, \theta, \mathrm{q} ; \mathrm{G}>$, where

$$
\begin{aligned}
\mathrm{EW} \equiv & \mathrm{E}_{\mu(1)} \mathrm{U}\left(\mathrm{c}_{1}, 1-\mathrm{L}\right)+\beta \mathrm{E}_{\mu(2) \mid \mu(1)} \mathrm{U}\left(\mathrm{c}_{2}, 1\right) \\
= & \mathrm{P}\left\{\left[\mathrm{U}\left(\mathrm{c}_{1}^{\mathrm{B}}, 1-\mathrm{L}^{\mathrm{B}}\right)\right]+\beta\left[\mathrm{qU}\left(\mathrm{c}_{2}^{\mathrm{BB}}, 1\right)+(1-\mathrm{q}) \mathrm{U}\left(\mathrm{c}_{2}^{\mathrm{BG}}, 1\right)\right]\right\} \\
& +(1-\mathrm{P})\left\{\left[\mathrm{U}\left(\mathrm{c}_{1}^{\mathrm{G}}, 1-\mathrm{L}^{\mathrm{G}}\right)\right]+\beta\left[(1-\mathrm{q}) \mathrm{U}\left(\mathrm{c}_{2}^{\mathrm{GB}}, 1\right)+\mathrm{qU}\left(\mathrm{c}_{2}^{\mathrm{GG}}, 1\right)\right]\right\} .
\end{aligned}
$$

The unconditional probability of the bad state $\mathrm{P}$ is set equal to $1 / 2$, and with equilibrium implying (to be shown shortly)

$$
\mathrm{c}_{2}^{\mathrm{BB}}=\mathrm{c}_{2}^{\mathrm{GB}}=\mathrm{c}_{2}^{\mathrm{B}} \text { and } \mathrm{c}_{2}^{\mathrm{BG}}=\mathrm{c}_{2}^{\mathrm{GG}}=\mathrm{c}_{2}^{\mathrm{G}}
$$


it follows that

$$
\begin{aligned}
\mathrm{EW} & =\mathrm{E}_{\mu(1)} \mathrm{U}\left(\mathrm{c}_{1}, 1-\mathrm{L}_{1}\right)+\beta \mathrm{E}_{\mu(2)} \mathrm{U}\left(\mathrm{c}_{2}, 1\right) \\
& =-\mathrm{A}\left(\overline{\mathrm{c}}_{1}-\mathrm{c}^{*}\right)^{2}-\mathrm{A} \sigma_{\mathrm{c}_{1}}^{2}-\mathrm{B} \overline{\mathrm{L}}^{2}-\mathrm{B} \sigma_{\mathrm{L}}^{2}-\beta \mathrm{A}\left(\overline{\mathrm{c}}_{2}-\mathrm{c}^{*}\right)^{2}-\beta \mathrm{A} \sigma_{\mathrm{c}_{2}}^{2}
\end{aligned}
$$

where $\left(^{(}\right)$and $\sigma_{(\cdot)}^{2}$ are unconditional means and variances, respectively.

As discussed earlier, it is useful to decompose EW in different ways in order to interpret the results. One way is by consumption and leisure, so that

$$
\begin{aligned}
& \mathrm{EW}\left[\mathrm{c}_{1}\right] \equiv-\mathrm{A}\left(\overline{\mathrm{c}}_{1}-\mathrm{c}^{*}\right)^{2}-\mathrm{A} \sigma_{\mathrm{c}_{1}}^{2}, \\
& \mathrm{EW}[\mathrm{L}] \equiv-\mathrm{B} \overline{\mathrm{L}}^{2}-\mathrm{B} \sigma_{\mathrm{L}}^{2},
\end{aligned}
$$

and

$$
\mathrm{EW}\left[\mathrm{c}_{2}\right] \equiv-\beta \mathrm{A}\left(\overline{\mathrm{c}}_{2}-\mathrm{c}^{*}\right)^{2}-\beta \mathrm{A} \sigma_{\mathrm{c}_{2}}^{2}
$$

The second way of decomposing $\mathrm{EW}$ is by distortion $\mathrm{EW}_{1}$ and instability $\mathrm{EW}_{2}$, where

$$
\mathrm{EW}_{1} \equiv-\mathrm{A}\left(\overline{\mathrm{c}}_{1}-\mathrm{c}^{*}\right)^{2}-\mathrm{BL}^{2}-\beta \mathrm{A}\left(\overline{\mathrm{c}}_{2}-\mathrm{c}^{*}\right)^{2}
$$

and

$$
\mathrm{EW}_{2} \equiv-\mathrm{A} \sigma_{\mathrm{c}_{1}}^{2}-\mathrm{B} \sigma_{\mathrm{L}}^{2}-\beta \mathrm{A} \sigma_{\mathrm{c}_{2}}^{2}
$$

Given numerical values of parameters, the solution for optimal values of $\tau_{1}, \tau_{2}$, and $\lambda$ is straightforward. For given parameter values and for given values of $\tau_{1}, \tau_{2}$, and $\lambda$, the individual's conditional supplies of labor, $\mathrm{L}^{\mathrm{B}}$ and $\mathrm{L}^{\mathrm{G}}$, and demands for real balances, $\mathrm{m}^{\mathrm{B}}$ and $\mathrm{m}^{\mathrm{G}}$, are determined as described in the previous section of this paper. All other equilibrium quantities are derived from the labor supply and money demand functions. In particular, quantities of consumption in each period in each state are derived. Thus, for given parameter values and arbitrary values of $\tau_{1}, \tau_{2}$, and $\lambda$, a value can be calculated for EW. We then adapt a program (Uncmin) written by Ellen McGrattan which uses a gradient methodology to find the values of $\tau_{1}, \tau_{2}$, and $\lambda$ that maximize EW. ${ }^{4}$ 
It follows from the budget constraints of the government and individuals that second-period outcomes depend only on the state in that period, not on the state in the previous period. For instance,

$$
\begin{aligned}
\operatorname{Tr}^{\mathrm{B}} & =\operatorname{Tr}^{\mathrm{BB}}=\operatorname{Tr}^{\mathrm{GB}}=\tau_{1} \mathrm{y}^{\mathrm{B}}+\tau_{2} \mathrm{y}^{\mathrm{B}^{2}}+\frac{\lambda \mathrm{M}(\mathrm{t})}{\mathrm{p}^{\mathrm{B}}(\mathrm{t}+1)}-\mathrm{G} \\
& =\tau_{1} \hat{\mathrm{L}}^{\mathrm{B}}+\tau_{2} \hat{\mathrm{L}}^{\mathrm{B}^{2}}+\frac{\lambda \hat{\mathrm{m}}^{\mathrm{B}}}{1+\lambda}-\mathrm{G}
\end{aligned}
$$

and similarly,

$$
\begin{aligned}
\operatorname{Tr}^{G} & =\operatorname{Tr}^{B G}=\operatorname{Tr}^{G G}=\tau_{1} y^{G}+\tau_{2} y^{G^{2}}+\frac{\lambda M(t)}{p^{G}(t+1)}-G \\
& =\tau_{1} \theta \hat{L}^{G}+\tau_{2} \theta^{2} \hat{L}^{G^{2}}+\frac{\lambda \hat{m}^{G}}{1+\lambda}-G .
\end{aligned}
$$

We then have

$$
\mathrm{c}_{2}^{\mathrm{B}}=\mathrm{c}_{2}^{\mathrm{BB}}=\mathrm{c}_{2}^{\mathrm{GB}}=\operatorname{Tr}^{\mathrm{B}}+\frac{\hat{\mathrm{m}}^{\mathrm{B}}}{1+\lambda}=\tau_{1} \hat{\mathrm{L}}^{\mathrm{B}}+\tau_{2} \hat{\mathrm{L}}^{\mathrm{B}^{2}}+\hat{\mathrm{m}}^{\mathrm{B}}-\mathrm{G}
$$

and

$$
\mathrm{c}_{2}^{\mathrm{G}}=\mathrm{c}_{2}^{\mathrm{BG}}=\mathrm{c}_{2}^{\mathrm{GG}}=\operatorname{Tr}^{\mathrm{G}}+\frac{\hat{\mathrm{m}}^{\mathrm{G}}}{1+\lambda}=\tau_{1} \theta \hat{\mathrm{L}}^{\mathrm{G}}+\tau_{2} \theta^{2} \hat{\mathrm{L}}^{\mathrm{G}^{2}}+\hat{\mathrm{m}}^{\mathrm{G}}-\mathrm{G}
$$

That second-period consumption depends only on the state in that period also can be seen to follow from the national income identity. Since there is no investment, it follows that for state $\mathrm{k}, \mathrm{k}$ $=\mathrm{B}$ or $\mathrm{G}$,

$$
\mathrm{c}_{1}^{\mathrm{k}}+\mathrm{c}_{2}^{\mathrm{k}}+\mathrm{G}=\mathrm{y}
$$

With $c_{1}^{k}=y^{k}-T^{k}-\hat{m}^{k}$, the above relationships for $c_{2}^{k}$ must hold.

Although all the relationships have been derived in the text, it is useful to summarize them in order to report the results of the exercises that follow. For $k=\mathrm{B}$ or $\mathrm{G}$, we have 


\section{Choice Variables}

Labor supply: $\mathrm{L}^{\mathrm{k}}$

Real money holdings: $\mathrm{m}^{\mathrm{k}}$.

\section{Income and Prices}

Income: $\mathrm{y}^{\mathrm{k}}=\mu^{\mathrm{k}} \mathrm{L}^{\mathrm{k}}$, where $\mu^{\mathrm{B}}=1$ and $\mu^{\mathrm{G}}=\theta>1$

Money stock: $\mathrm{M}(\mathrm{t})=(1+\lambda)^{\mathrm{t}}$

Price level: $\mathrm{p}(\mathrm{t})^{\mathrm{k}}=\mathrm{M}(\mathrm{t}) / \mathrm{m}^{\mathrm{k}}$.

\section{Government Budget}

Taxes: $\mathrm{T}^{\mathrm{k}}=\tau_{1} \mathrm{y}^{\mathrm{k}}+\tau_{2} \mathrm{y}^{\mathrm{k}^{2}}$

Government consumption: $\mathrm{G}$

Government transfers: $\operatorname{Tr}^{\mathrm{k}}=\mathrm{T}^{\mathrm{k}}+\lambda \mathrm{m}^{\mathrm{k}} /(1+\lambda)-\mathrm{G}$

Government expenditures: $E^{k}=G+\operatorname{Tr}^{k}$

Government deficit: $\mathrm{D}^{\mathrm{k}}=\mathrm{E}^{\mathrm{k}}-\mathrm{T}^{\mathrm{k}}$.

\section{Consumption}

First-period consumption: $c_{1}^{\mathrm{k}}=\mathrm{y}^{\mathrm{k}}-\mathrm{T}^{\mathrm{k}}-\mathrm{m}^{\mathrm{k}}$

Second-period consumption: $c_{2}^{\mathrm{k}}=\mathrm{T}^{\mathrm{k}}+\mathrm{m}^{\mathrm{k}}-\mathrm{G}$.

\section{Welfare}

Welfare criterion: $\mathrm{EW}=\mathrm{E}_{\mu(1)} \mathrm{U}\left(\mathrm{c}_{1}, 1-\mathrm{L}_{1}\right)+\beta \mathrm{E}_{\mu(2)} \mathrm{U}\left(\mathrm{c}_{2}, 1\right)$.

\section{Results}

The main issue addressed is how optimal policy decision variables $\tau_{1}, \tau_{2}$, and $\lambda$ change as government consumption $\mathrm{G}$ changes and how these changes in policy variables affect equilibrium 
values of other variables. Two auxiliary issues also are addressed: how the findings are altered when $\lambda$ is chosen optimally as opposed to being set at zero and how they are altered when there is serial correlation $\mathrm{q}>1 / 2$ as opposed to serial independence $\mathrm{q}=1 / 2$.

In order to address the main issue, we first assume numerical values for $\Psi \equiv$ $\left\langle\mathrm{A}, \mathrm{B}, \mathrm{c}^{*}, \beta, \theta, \mathrm{q} ; \mathrm{G}\right\rangle=\langle 2.0,10.0,4.0,0.9,1.5,0.5 ; \mathrm{G}\rangle$ and allow $\mathrm{G}$ to range from 0.00 to 0.20 by increments of 0.01 . This choice of parameter values generates reasonable labor supply functions (between zero and all the time available and upward sloping with respect to the real wage, e.g., productivity) and allows comparability to other tax structures in previous Miller (1984, 1993a) studies. Table 1 reports maximizing values for $\tau_{1}, \tau_{2}$, and $\lambda$ and equilibrium values for other quantities as $G$ increases by increments of 0.05 .

For the most part the policy decision variables change as expected to increases in government consumption G. The linear part of the income tax structure $\tau_{1}$ is the major part of the income tax, and it increases as $\mathrm{G}$ increases. In contrast the quadratic part of the income tax structure $\tau_{2}$ moves from a positive number to increasingly negative numbers. This indicates that the tax structure moves from one which is progressive to ones which are more and more regressive. The rate of money creation $\lambda$ increases as $G$ increases, but somewhat surprisingly it changes very little and remains negative for all values of G. Also surprising is that the changes in policy decision variables, as well as the changes in other variables in the table, indicate approximate linearity with respect to G. This is surprising because while the model is linear-quadratic with respect to consumption and leisure, it appears to be highly nonlinear with respect to the policy decision variables.

The means of budget variables reveal two big surprises. First, the table indicates how much of the increase in government consumption is absorbed by a cut in transfers. For instance, the table shows that when $\mathrm{G}$ increases from 0.0000 to 0.0500 , average transfers $\overline{\mathrm{T}} \mathrm{r}$ decline by 0.0495 , from 0.0186 to -0.0309 . Thus, average expenditures Ex increase by only 0.0005 , from 0.0186 to 0.0191 . 
The second surprise is that taxes $\overline{\mathrm{T}}$ increase by more than $\overline{\mathrm{E}}$, so that the government's budget surplus grows slightly as G increases. Evidently, the government's deflation subsidy grows even though the rate of deflation falls. As we see for the next set of variables, the deflation subsidy increases because real money holdings, the base for the deflation subsidy, rise more than the deflation rate declines.

Individual decision variables respond as expected to the changes in budget variables. Because their transfers in the second period decline, individuals wish to save more to replace some of that lost income. Therefore, they increase their demand for real savings $\mathrm{m}$, which drives down the price level. And because an increase in $G$ represents a loss in their income and consumption, the individuals desire to replace some of the loss by working more.

The means of consumption, labor, and income all behave as expected. The table indicates that as $\mathrm{G}$ increases, the loss is spread by agents over their consumption and leisure. This results in lower means for consumption in each period, higher average labor supply, and hence higher average output.

Although utility functions include variances of consumption and leisure as their measures of instability, the table next includes coefficients of variation. While they are not the proper measures of instability, they are independent of choice of units and are easier to interpret. The table indicates that as $\mathrm{G}$ increases, agents accept more variation in each period's consumption, in leisure, and in income.

The final set of variables illustrates two points. The first is that higher government consumption results in a welfare loss, as shown by declining values of EW. The second is that when agents and the government adapt optimally to higher government consumption, the welfare loss is distributed. Welfare associated with first-period consumption $\mathrm{EW}\left[\mathrm{c}_{1}\right]$, with labor EW[L], and with second-period consumption $\mathrm{EW}\left[\mathrm{c}_{2}\right]$ all decline. Agents accept both more distortion $\left(\right.$ lower $\left.\mathrm{EW}_{1}\right)$ and more instability (lower $\mathrm{EW}_{2}$ ). 
The results in Table 1, as well as those for intermediate values of G, are displayed in Figures 1-7. The figures indicate the relationships among the variables as well as the surprising linearity of the relationships of the variables with respect to $\mathrm{G}$.

A sensitivity analysis was conducted by doing versions of Figures 1-7 for different parameter values. New sets of parameters were constructed by changing $A, B, c^{*}, \beta$, and $\theta$ by about 10 percent from their initial values in Table 1. Perturbations were done one at a time. For all parameter sets the qualitative relationships shown in Figures 1-7 held.

Table 2 compares the outcomes for $\mathrm{G}=0$ when $\lambda$ is restricted to be zero and when it is chosen optimally. The first column comes from Miller (1993a). The second column is the same as the first column in Table 1. Table 2 shows that when the government is free to choose the rate of money growth, it shrinks the money stock. It finances the deflation subsidy with higher taxes and makes the tax structure more progressive. The reason for the greater progressivity is contained in Miller (1993a). The tax/transfer scheme in this model serves two purposes: it allows goods to be transferred across generations, and it provides insurance by (potentially) reducing income instability. When the government deflates, agents hold more real balances, as indicated in the table, and hence more of the transfer of goods to be handled through the money channel. The tax/transfer system is then used more for insurance, and more progressivity leads to less instability.

When the government deflates and has a more progressive income tax structure, the main effect on individuals is that they substitute from first- to second-period consumption. In the table $\overline{\mathrm{c}}_{1}$ declines by 0.0076 , from 0.6843 to 0.6767 , while $\overline{\mathrm{c}}_{2}$ rises by 0.0062 , from 0.3400 to 0.3462 . Similarly, EW[ $\left.\mathrm{c}_{1}\right]$ declines by 0.0989 , from -22.1482 to -22.2471 , while $\mathrm{EW}\left[\mathrm{c}_{2}\right]$ rises by 0.0815 , from -24.1139 to -24.0324 . Agents are also willing to trade off a little more distortion for a little less instability. 
Finally, Table 3 indicates how the results are affected by an increase in the assumed level of serial correlation in the productivity shock q. The table shows that the variables change qualitatively the same when $\mathrm{G}$ increases from 0.00 to 0.05 whether $\mathrm{q}=0.50,0.55$, or 0.60 (seen by comparing columns (1) and (2), (3) and (4), or (5) and (6)). However, as q rises, taxes T, transfers $\mathrm{Tr}$, and the deflation subsidy $-\lambda$ all decrease (seen by comparing columns (1), (3), and (5), or (2), (4), and (6)). While taxes fall, the degree of progressivity $\tau_{2}$ rises. As q rises, agents save more and work more, and the changes occur more in good states than in bad states. For instance, $\mathrm{L}^{\mathrm{B}}$ and $\mathrm{L}^{\mathrm{G}}$ both increase and $\mathrm{L}^{\mathrm{G}}$ increases more than $\mathrm{L}^{\mathrm{B}}$. These changes result in more consumption in each period. Accordingly $\mathrm{EW}\left[\mathrm{c}_{1}\right]$ and $\mathrm{EW}\left[\mathrm{c}_{2}\right]$ both rise while $\mathrm{EW}[\mathrm{L}]$ falls. The changes result in both lower distortion $\mathrm{EW}_{1}$ and less instability $\mathrm{EW}_{2}$. An interpretation is that a higher $\lambda$ increases predictability and lowers the probability that savers in a good state are going to face a low return on their savings when they are ready to spend them. Thus, they are willing to work and save more and, therefore, need less incentive to do so in terms of a lower $\tau_{2}$ and $\lambda$. Moreover, since they produce more in good times, the extra income has less marginal value, so that they are willing to transfer more to second-period consumption via a higher $\tau_{2}$.

\section{Conclusion}

The most striking finding of this analysis is that higher government consumption should be financed primarily by cuts in social security benefits. This finding goes so against the grain of current political thinking that it brings into question the validity of the model. Yet this finding is not as crazy as it initially seems.

The contrast between politicians' defense of social security and the model's attack on it can be attributed to two sources: 
1. Politicians care about the wishes of current voters, while the model is concerned about the current young and all future generations.

2. The social security system in practice involves a lot of redistribution among agents of the same generation, while the model's system involves none.

In terms of objective functions, it can be argued that voters' choices do not properly account for the welfare of future generations, so that their choices are suboptimal in terms of social welfare. That is, in the case of social security, voters might choose to protect it, when in the country's longrun interest, as represented by the model's social welfare function, it should be diminished.

However, even from a social welfare point of view, the model's EW function can be properly criticized for ignoring the utility of the initial old, and those agents would clearly be hurt by a cut in social security payments. Including the utility of the initial old would imply that a cut in social security payments would not be Pareto optimal. Yet if a welfare function were assumed that was a discounted sum of utilities of the initial old, the initial young, and all future generations, and the discount rate $\delta$ on $\sum_{t=0}^{\infty} \delta^{t} U_{t}$ were not too low, then the welfare gains of the initial young and all future generations would overwhelm the welfare loss of the initial old. Thus, voters' preferences may be an inadequate guide to what is in the long-run interests of the economy. A social welfare function which does provide an adequate guide and incorporates the utility of the current old is not likely to overturn the model's finding about the desirability of reducing social security in light of a permanent increase in government consumption.

But that finding would have to be tempered in applying it to our current system. The current system can be thought of as a redistribution from the young to the old as well as a redistribution among the old. The model's system involves a redistribution only from the young to the old. The model thus suggests that if government consumption permanently increased, it would be best to alter tax rates just a little and finance the majority of the increase by a cut in social security benefits to 
middle- and upper-income individuals. By cutting these benefits the young and future generations could best adapt their employment and private savings decisions to the loss implied by higher government consumption. This logic is similar to that used by Feldstein (1987), Miller (1993b), and Becker and Ehrlich (1994) in arguing to replace the intergenerational transfer part of social security with a private pension system.

With all this said, one could still wonder what the model would imply if social security could not be touched, as the current political climate would demand. This might be implemented in the model by fixing transfers at their optimal levels for $G=0$, so that when $G$ increases, the transfers stay at those levels. Since the transfers don't fully absorb the increases in G when they are free to adjust, one can be confident that the qualitative results of the model with respect to taxes will still hold when transfers don't absorb any of the increases in G: explicit taxes will increase; the rise in taxes will create more distortion, causing the tax structure to become more regressive—-that is, $\tau_{1}$ will increase and $\tau_{2}$ will decrease—and since both explicit and implicit taxes distort, desirable policies will spread the distortion, causing the rate of money creation to increase. The question which does not have a readily apparent answer is, Could $\lambda$ ever become positive? A guess is that it could, since agents would want to lower their leisure and consumption in each period, and with transfers fixed a higher $\lambda$ is the main incentive for agents to save less and consume less in their second period. Thus, if $\mathrm{G}$ became large enough, it would seem that $\lambda$ could go positive.

Given misgivings some may have about some of the model's assumptions, it seems reasonable to wonder which of the findings are likely to be robust. I suggest three:

1. The desired level of social security benefits cannot be considered independently. It depends on what's going on in the rest of the budget, with respect to both expenditures and taxes. This has long been the CBO's (1992, pp. 33ff) position. 
2. As government spending increases, the income tax structure should become more regressive to serve efficiency. As the tax burden rises, tax distortion becomes more of a problem which regressivity can mitigate.

3. As government spending increases, the optimal rate of money growth should increase. Since all available taxes distort, a higher tax burden should be spread among all taxes, both explicit and implicit. 
Notes

${ }^{1}$ Models following the standard approach include Chari, Christiano, and Kehoe (1994), and Krussel, Quadrini, and Rios-Rull (1995). Auerbach and Kotlikoff (1987) use an overlapping generations structure as in my model, but their agents live for many periods and that would tend to prevent valued fiat money. Thus, while their model can be calibrated, they analyze public finance questions in a real economy. Much of the focus of my research is to examine such questions in a monetary economy.

${ }^{2}$ It is shown in this model that if a government has access to lump-sum taxes, the tax should be higher in the good state than in the bad state. This indicates a role for economic stabilization, since if minimal distortion were the sole goal, a lump-sum tax constant across states would do.

3“B" and "G" also denote, respectively, a parameter in the utility function and government consumption. However, the notation should not lead to confusion, since when, and only when, B and $G$ appear as superscripts, do they represent states of technology.

${ }^{4}$ McGrattan's solution method requires good initial estimates of the maximizers. When $\mathrm{G}=0$, initial values for $\tau_{1}, \tau_{2}$, and $\lambda$ are chosen by using a grid search to find the maximizing values of $\tau_{1}$ and $\tau_{2}$ with $\lambda$ restricted to be 0 . For each incrementally higher value of $G, G_{i}=G_{i-1}$ $+\Delta \mathrm{G}$, the initial estimates of $\tau_{1}, \tau_{2}$, and $\lambda$ for $\mathrm{G}_{\mathrm{i}}$ are the maximizing values found for $\mathrm{G}_{\mathrm{i}-1}$. After finding McGrattan's solution, we do a grid search to increase the precision of the solution. 


\section{References}

Auerbach, Alan J., and Kotlikoff, Laurence J. 1987. Dynamic fiscal policy. Cambridge, Mass.: Cambridge University Press.

Becker, Gary S., and Ehrlich, Isaac. 1994. Social security: Foreign lessons. Wall Street Journal, March 30: A18.

Chari, V. V.; Christiano, Lawrence J.; and Kehoe, Patrick J. 1994. Optimal fiscal policy in a business cycle model. Journal of Political Economy 102 (August): 617-52.

Congressional Budget Office (CBO). 1992. The economic and budget outlook: Fiscal years 1993-1997. A report to the Senate and House committees on the budget, January. Washington, D.C.: U.S. Government Printing Office.

Feldstein, Martin S. 1987. The welfare cost of social security's impact on private saving. In Modern developments in public finance: Essays in honor of Arnold Harberger, ed. Michael J. Boskin, pp. 1-13. New York: Basil Blackwell.

Krusell, Per; Quadrini, Vincenzo; and Ríos-Rull, José-Víctor. 1995. Are consumption taxes really better than income taxes? Manuscript. University of Pennsylvania.

Miller, Preston J. 1984. Income stability and economic efficiency under alternative tax schemes. In Monetary and fiscal policies and their application, ed. Karl Brunner and Allan H. Meltzer. Carnegie-Rochester Conference Series on Public Policy 20 (Spring): 121-41.

. 1993a. Optimal income tax in a monetary economy. Journal of Economic Dynamics and Control 17 (May): 443-65.

. 1993b. The high cost of being fair. In Federal Reserve Bank of Minneapolis 1993

annual report, pp. 2-19. Minneapolis, Minn.: Federal Reserve Bank of Minneapolis. 
Table 1

$\left[\mathrm{A}, \mathrm{B}, \mathrm{c}^{*}, \beta, \theta, \mathrm{q}\right]=[2,10,4,0.9,1.5,0.5]$

\begin{tabular}{|c|c|c|c|c|c|}
\hline \multirow[b]{2}{*}{ Variable } & \multicolumn{5}{|c|}{ Value of Variable When $G=$} \\
\hline & 0 & .0500 & .1000 & .1500 & .2000 \\
\hline$\tau_{1}$ & .0173 & .0189 & .0207 & .0221 & .0235 \\
\hline$\tau_{2}$ & .0009 & .0000 & -.0010 & -.0018 & -.0026 \\
\hline$\lambda$ & -.0042 & -.0041 & -.0040 & -.0038 & -.0037 \\
\hline$\overline{\mathrm{T}} \mathrm{r}$ & .0186 & -.0309 & -.0802 & -.1296 & -.1788 \\
\hline$\overline{\mathrm{T}}$ & .0199 & .0205 & .0213 & .0219 & .0228 \\
\hline $\bar{E} x$ & .0186 & .0191 & .0198 & .0204 & .0212 \\
\hline Def & -.0013 & -.0014 & -.0015 & -.0015 & -.0016 \\
\hline $\mathrm{m}^{\mathrm{B}}$ & .2986 & .3229 & .3470 & .3711 & .3953 \\
\hline $\mathrm{m}^{\mathrm{G}}$ & .3540 & .3826 & .4109 & .4392 & .4675 \\
\hline $\mathrm{L}^{\mathrm{B}}$ & .7067 & .7107 & .7146 & .7185 & .7223 \\
\hline $\mathrm{L}^{\mathrm{G}}$ & .8928 & .8991 & .9057 & .9121 & .9185 \\
\hline$\overline{\mathrm{c}}_{1}$ & .6767 & .6565 & .6362 & .6162 & .5959 \\
\hline$\overline{\mathrm{L}}$ & .7998 & .8049 & .8101 & .8153 & .8204 \\
\hline$\overline{\mathrm{c}}_{2}$ & .3462 & .3232 & .3003 & .2771 & .2542 \\
\hline $\bar{y}$ & 1.0230 & 1.0297 & 1.0365 & 1.0433 & 1.0501 \\
\hline $\operatorname{cv}\left(c_{1}\right)$ & $41.6686 \%$ & $43.0576 \%$ & $44.5633 \%$ & $46.1438 \%$ & $47.8541 \%$ \\
\hline $\operatorname{cv}(\mathrm{L})$ & $11.6306 \%$ & $11.7059 \%$ & $11.7953 \%$ & $11.8744 \%$ & $11.9594 \%$ \\
\hline $\operatorname{cv}\left(c_{2}\right)$ & $9.8845 \%$ & $11.2436 \%$ & $12.8011 \%$ & $14.6170 \%$ & $16.7577 \%$ \\
\hline $\operatorname{cv}(y)$ & $30.9116 \%$ & $30.9806 \%$ & $31.0625 \%$ & $31.1349 \%$ & $31.2129 \%$ \\
\hline EW & -52.7622 & -53.4218 & -54.0855 & -54.7533 & -55.4253 \\
\hline $\mathrm{EW}\left[\mathrm{c}_{1}\right]$ & -22.2471 & -22.5180 & -22.7905 & -23.0624 & -23.3384 \\
\hline $\mathrm{EW}[\mathrm{L}]$ & -6.4827 & -6.5677 & -6.6541 & -6.7404 & -6.8273 \\
\hline $\mathrm{EW}\left[\mathrm{c}_{2}\right]$ & -24.0324 & -24.3361 & -24.6409 & -24.9505 & -25.2596 \\
\hline $\mathrm{EW}_{1}$ & -52.5145 & -53.1708 & -53.8307 & -54.4950 & -55.1631 \\
\hline $\mathrm{EW}_{2}$ & -.2477 & -.2510 & -.2547 & -.2583 & -.2622 \\
\hline
\end{tabular}


Table 2

Parameters $\left\langle\mathrm{A}, \mathrm{B}, \mathrm{c}^{*}, \beta, \theta, \mathrm{q}\right\rangle=\langle 2,10,4,0.9,1.5,0.5\rangle$,

$$
\mathrm{G}=0.00
$$

\begin{tabular}{|c|c|c|}
\hline Variable & $\lambda \equiv 0$ & $\lambda$ endog. \\
\hline$\hat{\tau}_{1}$ & .0157 & .0173 \\
\hline$\hat{\tau}_{2}$ & .0006 & .0009 \\
\hline$\hat{\lambda}$ & .0000 & -.0042 \\
\hline$\overline{\mathrm{T}} \mathrm{r}$ & .0168 & .0186 \\
\hline$\overline{\mathrm{T}}$ & .0168 & .0199 \\
\hline $\bar{E} x$ & .0168 & .0186 \\
\hline Def & .0000 & -.0013 \\
\hline $\mathrm{m}^{\mathrm{B}}$ & .2956 & .2986 \\
\hline $\mathrm{m}^{\mathrm{G}}$ & .3508 & .3540 \\
\hline $\mathrm{L}^{\mathrm{B}}$ & .7080 & .7067 \\
\hline $\mathrm{L}^{\mathrm{G}}$ & .8938 & .8928 \\
\hline$\overline{\mathrm{c}}_{1}$ & .6843 & .6767 \\
\hline$\overline{\mathrm{L}}$ & .8009 & .7998 \\
\hline$\overline{\mathrm{c}}_{2}$ & .3400 & .3462 \\
\hline$\overline{\mathrm{y}}$ & 1.0243 & 1.0230 \\
\hline$\sigma_{\mathrm{c}_{1}} / \overline{\mathrm{c}}_{1}$ & $41.4 \%$ & $41.7 \%$ \\
\hline$\sigma_{\mathrm{L}} / \overline{\mathrm{L}}$ & $11.6 \%$ & $11.6 \%$ \\
\hline$\sigma_{\mathrm{c}_{2}} / \overline{\mathrm{c}}_{2}$ & $9.7 \%$ & $9.9 \%$ \\
\hline$\sigma_{y}^{2} / \bar{y}$ & $30.9 \%$ & $30.9 \%$ \\
\hline EW & -52.7624 & -52.7622 \\
\hline $\mathrm{EW}\left[\mathrm{c}_{1}\right]$ & -22.1482 & -22.2471 \\
\hline $\mathrm{EW}[\mathrm{L}]$ & -6.5004 & -6.4827 \\
\hline $\mathrm{EW}\left[\mathrm{c}_{2}\right]$ & -24.1139 & -24.0324 \\
\hline $\mathrm{EW}_{1}$ & -52.5133 & -52.5145 \\
\hline $\mathrm{EW}_{2}$ & -.2491 & -.2477 \\
\hline
\end{tabular}


Table 3

$\left[\mathrm{A}, \mathrm{B}, \mathrm{c}^{*}, \beta, \theta\right]=[2,10,4,0.9,1.5]$

\begin{tabular}{|c|c|c|c|c|c|c|}
\hline \multirow[b]{2}{*}{ Variable } & \multicolumn{2}{|c|}{$q=0.50$} & \multicolumn{2}{|c|}{$q=0.55$} & \multicolumn{2}{|c|}{$q=0.60$} \\
\hline & $\begin{array}{c}\mathrm{G}=0.00 \\
(1)\end{array}$ & $\begin{array}{c}\mathrm{G}=0.05 \\
(2)\end{array}$ & $\begin{array}{c}\mathrm{G}=0.00 \\
\text { (3) }\end{array}$ & $\begin{array}{c}\mathrm{G}=0.05 \\
(4)\end{array}$ & $\begin{array}{c}\mathrm{G}=0.00 \\
(5)\end{array}$ & $\begin{array}{c}\mathrm{G}=0.05 \\
(6)\end{array}$ \\
\hline$\tau_{1}$ & .0173 & .0189 & .0140 & .0160 & .0108 & .0130 \\
\hline$\tau_{2}$ & .0009 & .0000 & .0017 & .0006 & .0024 & .0012 \\
\hline$\lambda$ & -.0042 & -.0041 & -.0037 & -.0036 & -.0032 & -.0030 \\
\hline$\overline{\mathrm{T}} \mathrm{r}$ & .0186 & -.0309 & -.0163 & -.0331 & .0140 & -.0352 \\
\hline$\overline{\mathrm{T}}$ & .0199 & .0205 & .0175 & .0182 & .0150 & .0158 \\
\hline$\overline{E x}$ & .0186 & .0191 & .0163 & .0169 & .0140 & .0148 \\
\hline Def & -.0013 & -.0014 & -.0012 & -.0012 & -.0010 & -.0010 \\
\hline $\mathrm{m}^{\mathrm{B}}$ & .2986 & .3229 & .2990 & .3230 & .2990 & .3266 \\
\hline $\mathrm{m}^{\mathrm{G}}$ & .3540 & .3826 & .3600 & .3886 & .3668 & .3952 \\
\hline $\mathrm{L}^{\mathrm{B}}$ & .7067 & .7107 & .7078 & .7117 & .7088 & .7126 \\
\hline $\mathrm{L}^{\mathrm{G}}$ & .8928 & .8991 & .8941 & .9007 & .8957 & .9022 \\
\hline$\overline{\mathrm{c}}_{1}$ & .6767 & .6565 & .6775 & .6574 & .6783 & .6582 \\
\hline$\overline{\mathrm{L}}$ & .7998 & .8049 & .8010 & .8062 & .8023 & .8074 \\
\hline$\overline{\mathrm{c}}_{2}$ & .3462 & .3232 & .3470 & .3240 & .3480 & .3247 \\
\hline $\bar{y}$ & 1.0230 & 1.0297 & 1.0245 & 1.0314 & 1.0262 & 1.0330 \\
\hline $\operatorname{cv}\left(c_{1}\right)$ & $41.6686 \%$ & $43.0576 \%$ & $41.3551 \%$ & $42.7372 \%$ & $40.9933 \%$ & $42.3264 \%$ \\
\hline $\operatorname{cv}(\mathrm{L})$ & $11.6306 \%$ & $11.7059 \%$ & $11.6315 \%$ & $11.7231 \%$ & $11.6493 \%$ & $11.7447 \%$ \\
\hline $\operatorname{cv}\left(c_{2}\right)$ & $9.8845 \%$ & $11.2436 \%$ & $10.5213 \%$ & $11.9613 \%$ & $11.3102 \%$ & $12.8649 \%$ \\
\hline $\operatorname{cv}(y)$ & $30.9116 \%$ & $30.9806 \%$ & $30.9124 \%$ & $30.9963 \%$ & $30.9287 \%$ & $31.0162 \%$ \\
\hline EW & -52.7622 & -53.4218 & -52.7596 & -53.4191 & -52.7566 & -53.4158 \\
\hline $\mathrm{EW}\left[\mathrm{c}_{1}\right]$ & -22.2471 & -22.5180 & -22.2347 & -22.5044 & -22.2225 & -22.4898 \\
\hline $\mathrm{EW}[\mathrm{L}]$ & -6.4827 & -6.5677 & -6.5022 & -6.5890 & -6.5239 & -6.6091 \\
\hline $\mathrm{EW}\left[\mathrm{c}_{2}\right]$ & -24.0324 & -24.3361 & -24.0227 & -24.3256 & -24.0102 & -24.3169 \\
\hline $\mathrm{EW}_{1}$ & -52.5145 & -53.1708 & -52.5134 & -53.1692 & -52.5118 & -53.1675 \\
\hline $\mathrm{EW}_{2}$ & -.2477 & -.2510 & -.2462 & -.2499 & -.2447 & -.2483 \\
\hline
\end{tabular}


Figure $1 \quad A=2, B=10, c^{*}=4.0$, beta $=0.9$, theta $=1.6$

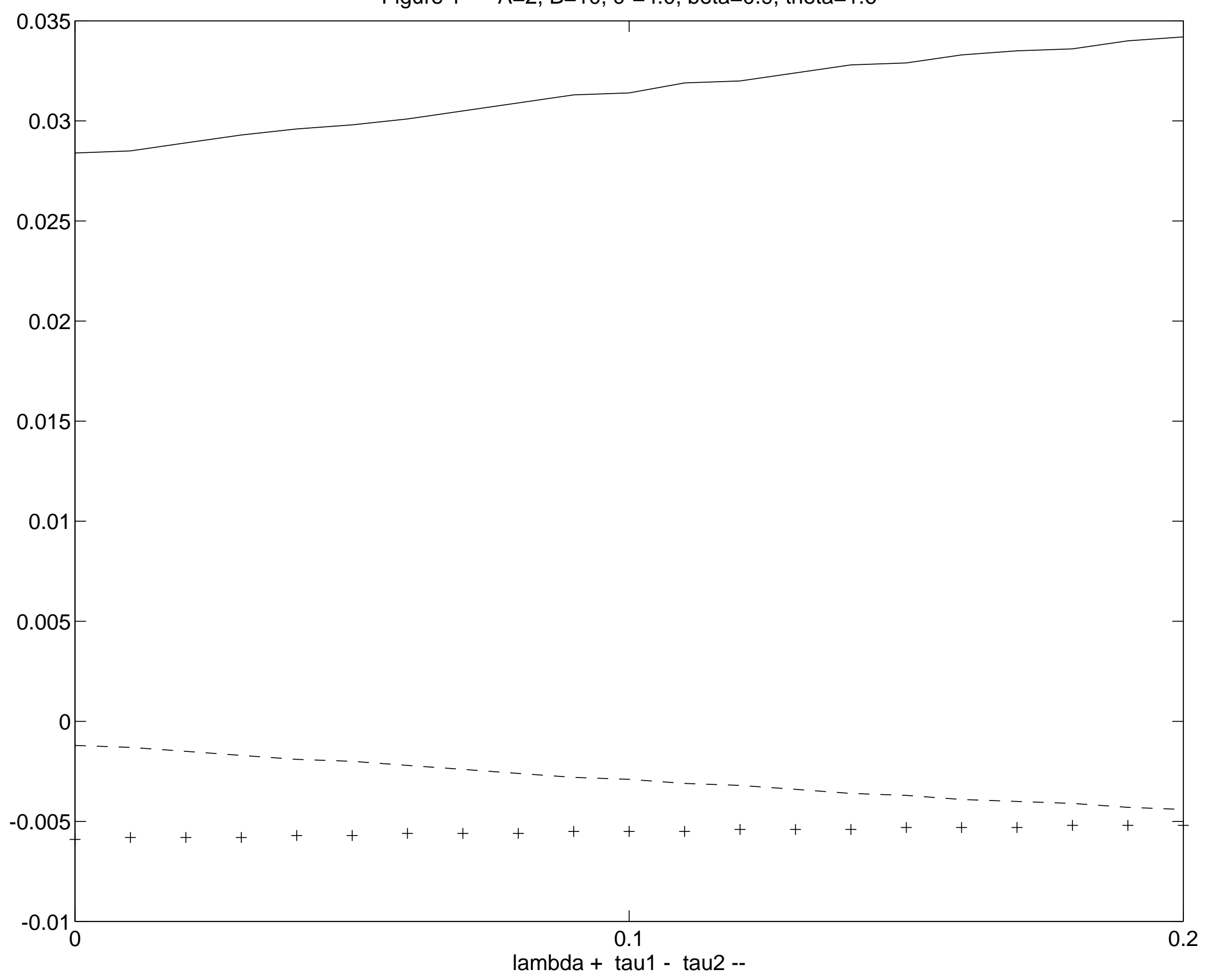


Figure $2 \quad A=2, B=10, c^{*}=4.0$, beta $=0.9$, theta $=1.6$

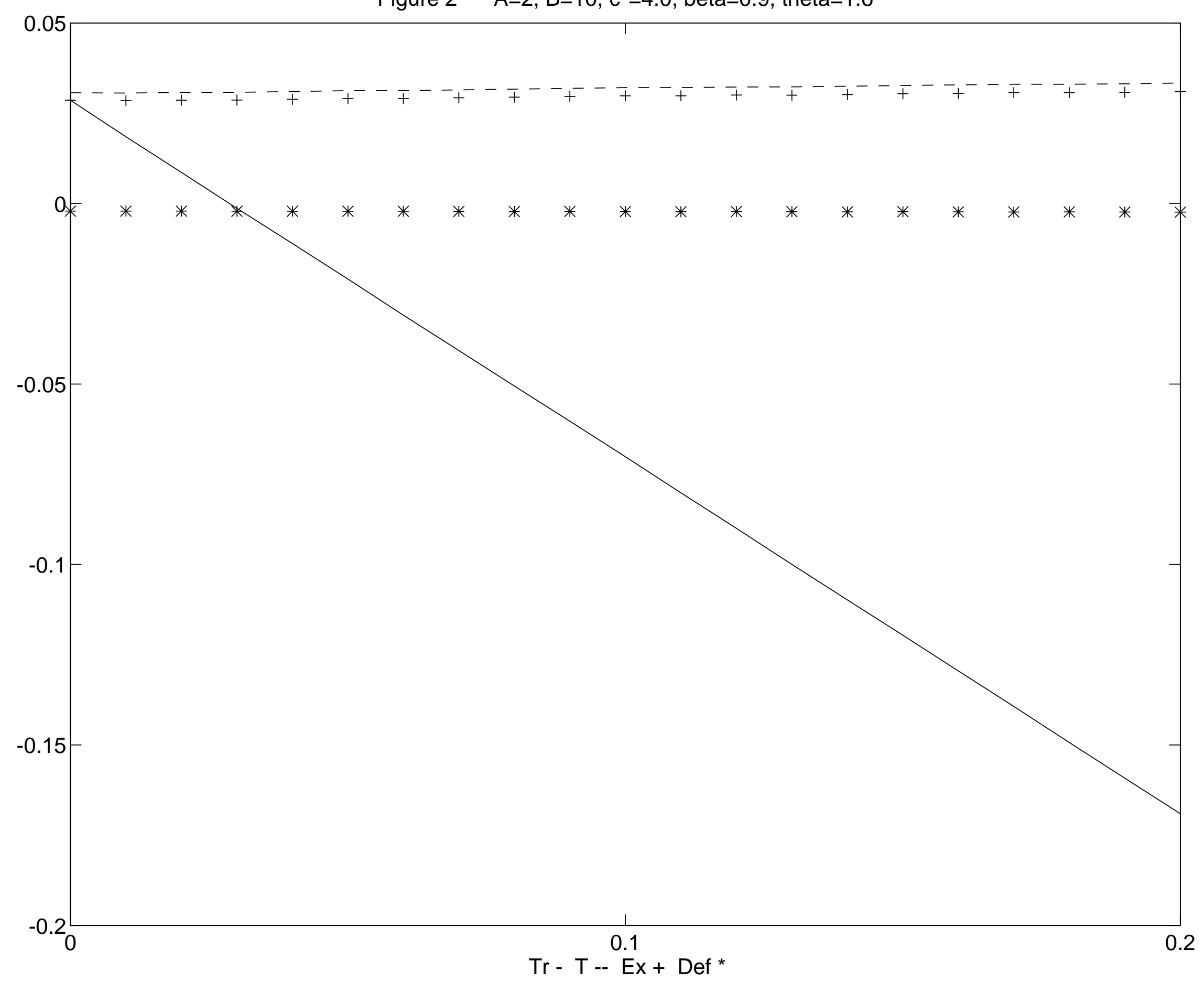


Figure $3 \quad A=2, B=10, c^{*}=4.0$, beta $=0.9$, theta $=1.6$

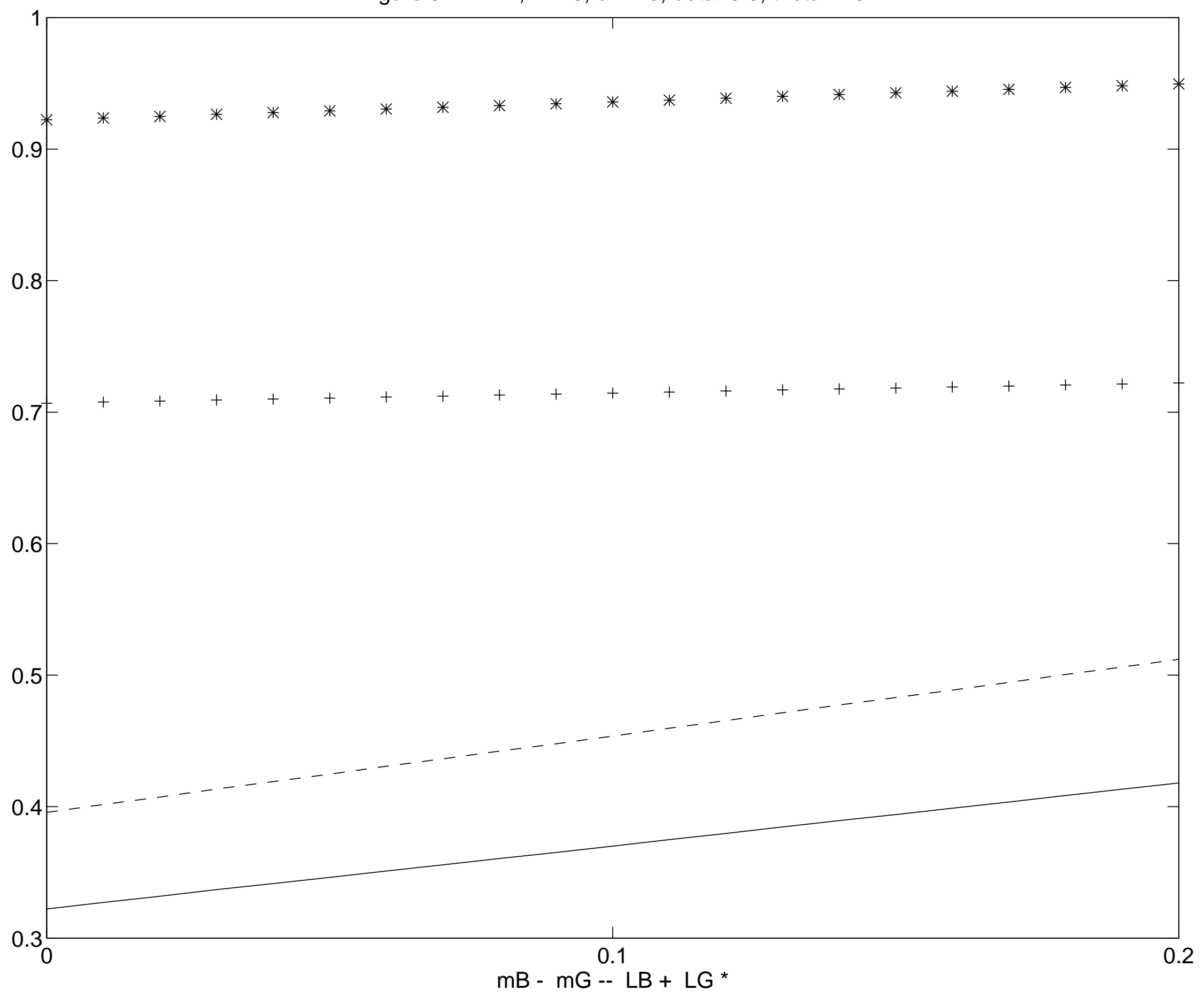


Figure $4 \quad A=2, B=10, c^{*}=4.0$, beta $=0.9$, theta $=1.6$

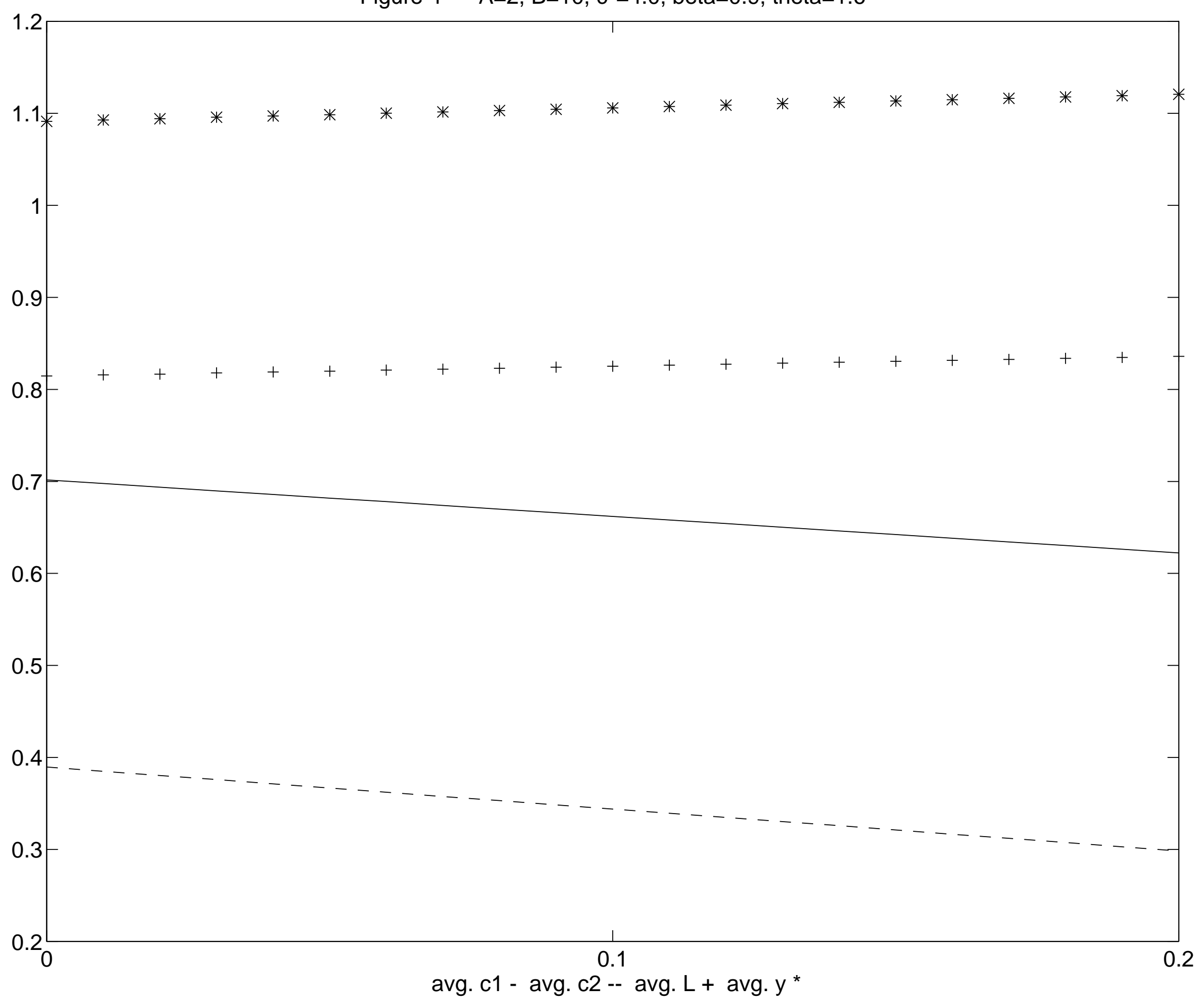


Figure $5 \quad A=2, B=10, c^{*}=4.0$, beta $=0.9$, theta $=1.6$

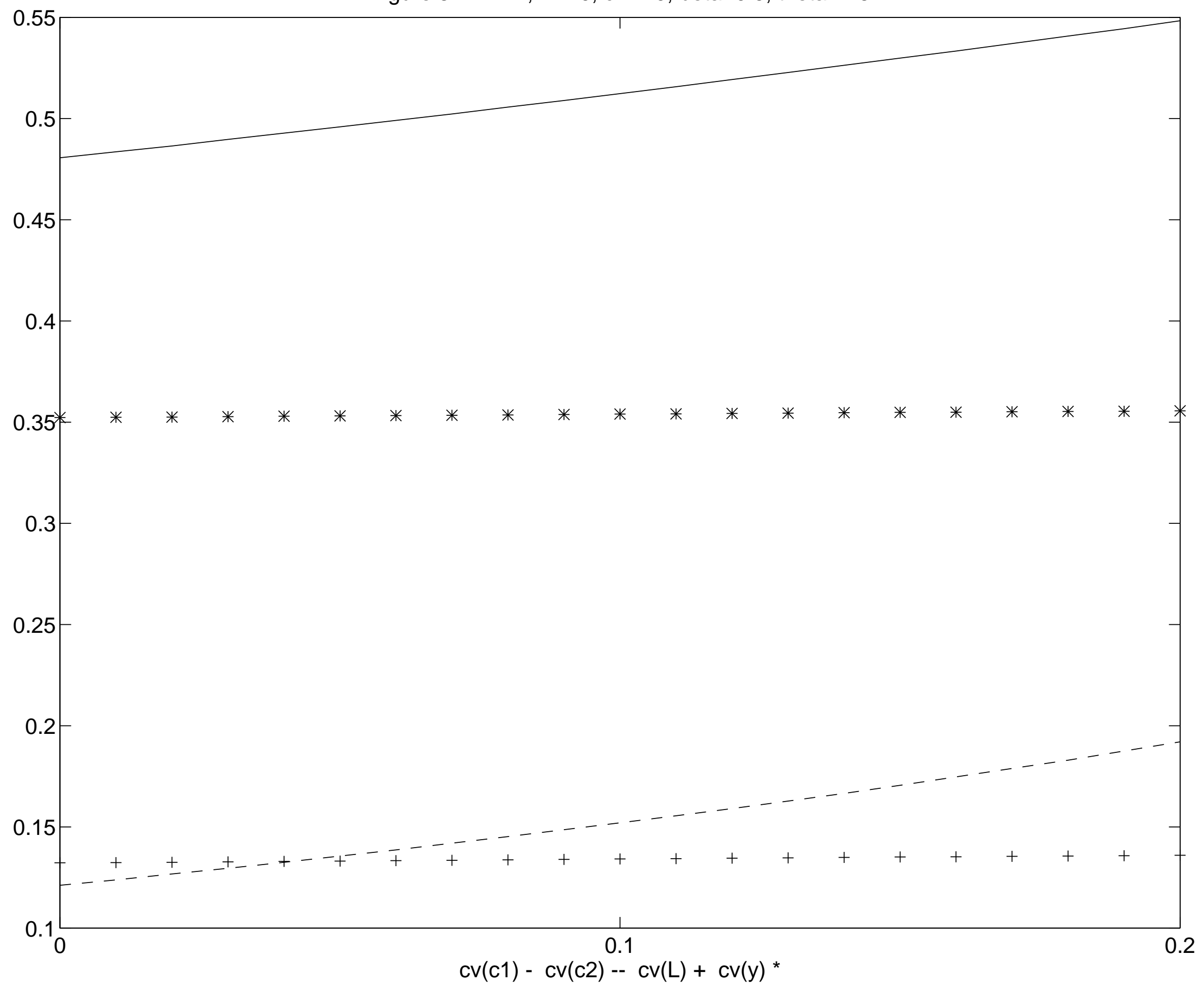


Figure $6 \quad A=2, B=10, c^{*}=4.0$, beta $=0.9$, theta $=1.6$

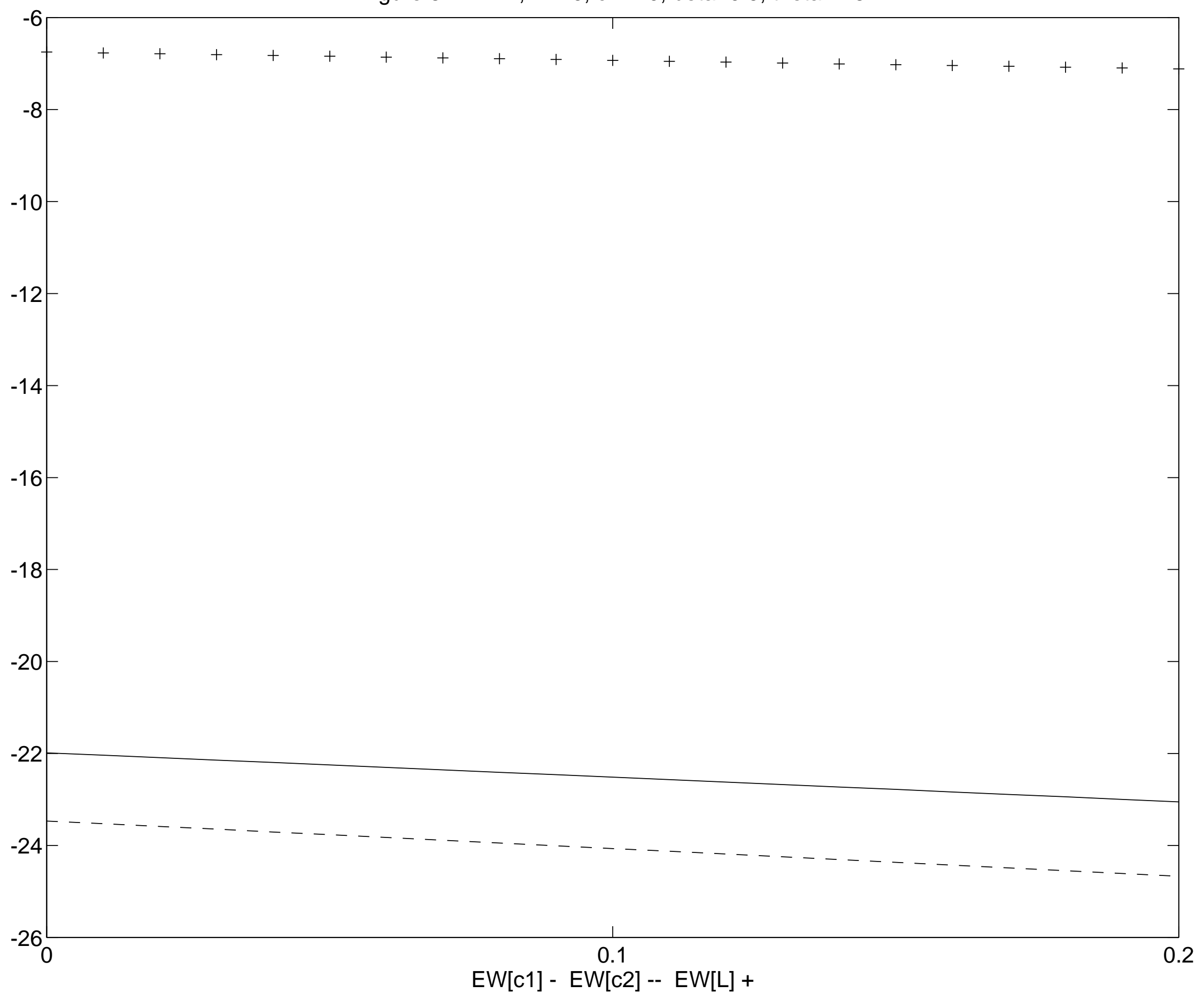


Figure $7 \quad A=2, B=10, c^{*}=4.0$, beta $=0.9$, theta $=1.6$

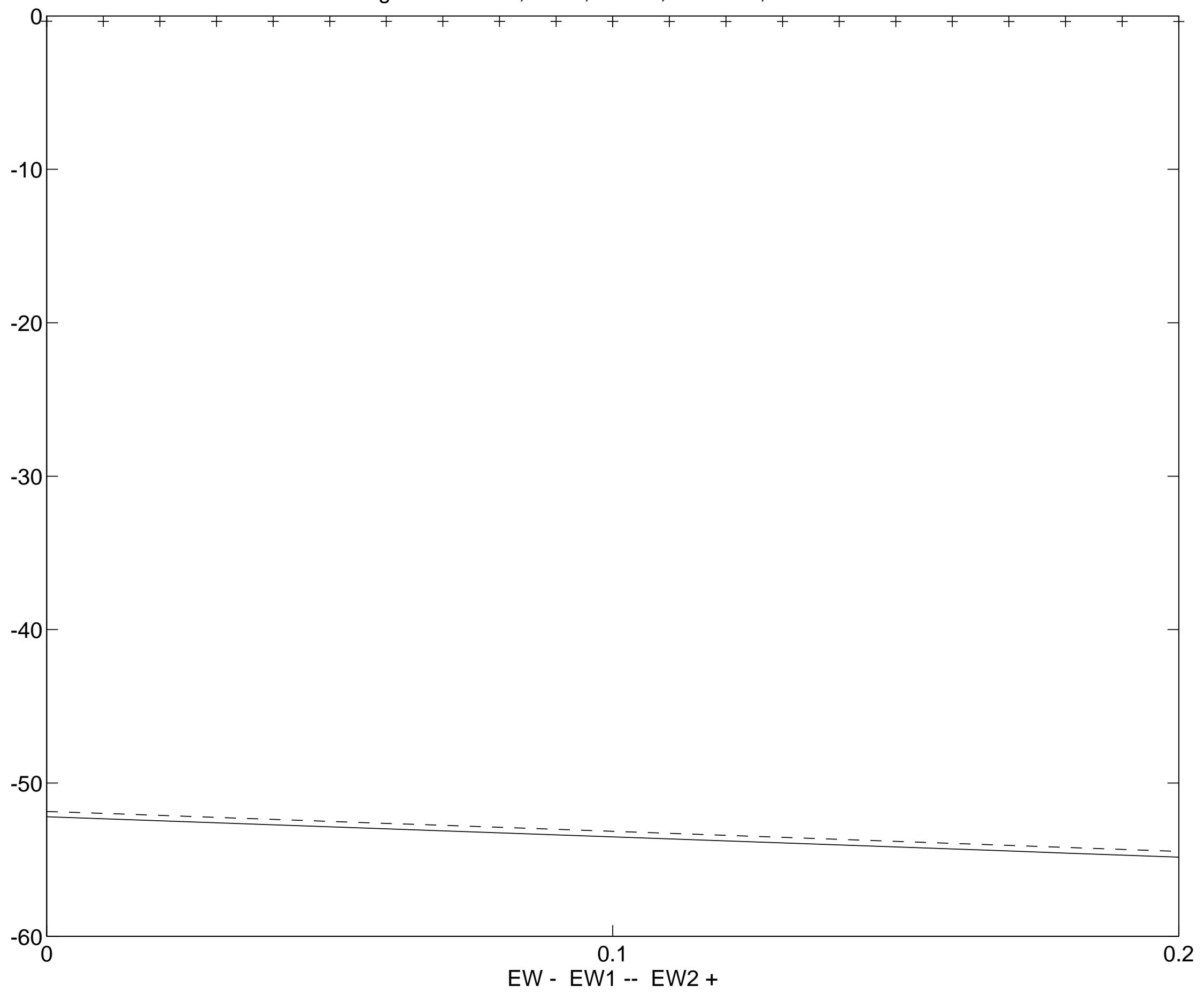

